\title{
Modifikasi Route Discovery pada Ad-hoc on Demand Distance Vector (AODV) Berdasarkan Level Konektivitas One-Hop Node di VANETs
}

\author{
Aviananda Dwirahma J, Radityo Anggoro, dan Supeno Djanali \\ Departemen Informatika, Fakultas Teknologi Informasi dan Komunikasi, Institut Teknologi Sepuluh \\ Nopember (ITS) \\ e-mail: onggo@if.its.ac.id
}

\begin{abstract}
Abstrak-Vehicular Ad hoc Networks (VANETs) merupakan pengembangan dari Mobile Ad hoc Network (MANET) dimana node memiliki karakteristik dengan mobilitas yang sangat tinggi dan terbatas pada pola pergerakannya. Ada banyak routing protocol yang dapat diimplementasikan pada VANETs, salah satunya adalah Ad hoc On demand Distance Vector (AODV).

AODV merupakan salah satu routing protocol yang termasuk dalam klasifikasi reactive routing protocol, sebuah protokol yang hanya akan membuat rute ketika node sumber membutuhkannya. AODV memiliki dua fase, yaitu route discovery dan route maintenance. Route discovery digunakan untuk meminta dan meneruskan informasi rute yang terdiri dari proses pengiriman Route Request (RREQ) dan Route Reply (RREP). Modifikasi pada Studi ini akan dilakukan pada proses route discovery berdasarkan level konektivitas one-hop node, yaitu dengan cara mengeliminasi jumlah forwarding node yang bertugas untuk mengirim ulang ( $r e$ broadcast) RREQ. Hal ini dilakukan agar dapat meningkatkan kinerja protokol AODV untuk mencari rute yang stabil dengan cara memodifikasi beberapa bagian dari mekanisme pengiriman paket RREQ. Dari hasil uji coba, AODV yang dimodifikasi berhasil meningkatkan nilai Packet Delivery Ratio (PDR) hingga 9,19\%, penurunan nilai Routing Overhead (RO) hingga 2,17\%, dan penurunan nilai Forwarded Route Request (RREQ F) hingga $31,62 \%$.
\end{abstract}

Kata Kunci-AODV, Forwarding Node, NS-2, One-Hop Node, Threshold, VANETs.

\section{PENDAHULUAN}

CAAT ini perkembangan teknologi informasi dan Nomunikasi menjadi salah satu indikator kemajuan peradaban manusia. Salah satu teknologi yang membantu manusia dalam berkomunikasi dengan mudah adalah Vehicular Ad hoc Networks (VANETs). VANETs merupakan suatu mekanisme yang dapat menghubungkan kendaraan satu dengan yang lainnya menggunakan jaringan nirkabel. VANETs dapat berguna pada banyak hal, seperti mengemudi secara otomatis, navigasi, pencegahan kecelakaan yang dapat meningkatkan keamanan berkendara, serta dapat mengurangi kemacetan lalu lintas [1].

Pada Studi ini diusulkan suatu mekanisme routing discovery pada reactive routing AODV untuk memperoleh rute berdasarkan level konektivitas one-hop pada VANETs. Penulis mengadaptasi cara kerja OLSR dimana hanya beberapa node yang terpilih sebagai node perantara untuk Tabel 1.

Parameter Simulasi meneruskan paket dan mengurangi control packet yang terlalu banyak [2]. Node tersebut hanya memilih beberapa node tetangga yang akan menjadi node perantara, dan hanya node perantara yang dapat meneruskan Route Request (RREQ), sedangkan node lainnya tidak akan meneruskan (drop) paket tersebut. Metode yang digunakan untuk mendeteksi node tetangga menggunakan HELLO messages yang terdapat pada AODV yang dikirim secara periodic untuk mengetahui simpul tetangga pada suatu waktu [3]. Hasil akhir yang diharapkan adalah mengetahui perbandingan kinerja antara AODV dan AODV yang telah dimodifikasi diukur berdasarkan performansi Packet Delivery Ratio (PDR), Routing Overhead, End-to-End Delay, dan Forwarded Route Request (RREQ F).

\section{ANALISIS DAN PERANCANGAN}

\section{A. Vehicular Ad-hoc Networks (VANETs)}

Vehicular Ad-hoc Networks (VANETs) merupakan pengembangan dari Mobile Ad-hoc Network (MANET) dimana pengembangannya difokuskan pada kendaraan (vehicle) yang dapat saling berkomunikasi maupun mengirimkan data. VANETs adalah sebuah teknologi baru yang memadukan kemampuan komunikasi nirkabel kendaraan menjadi sebuah jaringan yang bebas infrastuktur serta memiliki karakteristik mobilitas yang sangat tinggi dan terbatas pada pola pergerakannya. Node dalam jaringan dianggap sebagai router yang bebas bergerak dan bebas menentukan baik menjadi client maupun menjadi router. Protokol routing pada VANETs memiliki dua model yaitu protokol reactive routing yang membentuk tabel routing hanya saat dibutuhkan dan protokol proactive routing yang melakukan pemeliharaan tabel routing secara berkala pada waktu tertentu. Pergerakan node pada VANETs bisa berubah setiap saat dan terbatas pada rute lalu lintas yang dapat ditentukan dari koordinat peta. Hal ini membuat setiap node akan terus memperbarui informasi dalam tabelnya sesuai informasi dari node lain. Perubahaan pergerakan pada VANETs menjadi salah satu permasalahan dalam pengiriman paket data sehingga dibutuhkan informasi jarak antar node, kecepatan dan delay transmisi [4]. Ilustrasi VANETs dapat dilihat pada Gambar 1.

\begin{tabular}{lll}
\hline \hline No. & Parameter & Spesifikasi \\
\hline
\end{tabular}




\begin{tabular}{lcc}
\hline 1 & Network simulator & NS-2.35 \\
2 & Routing protocol & AODV \\
3 & Waktu simulasi & 200 detik \\
4 & Area simulasi & $1500 \mathrm{~m} \mathrm{x} 1500 \mathrm{~m}$ \\
5 & Jumlah Node & $60,150,300$ \\
6 & Radius transmisi & $400 \mathrm{~m}$ \\
7 & Kecepatan maksimum & $20 \mathrm{~m} / \mathrm{s}$ \\
8 & Protokol MAC & IEEE $802.11 \mathrm{p}$ \\
9 & Model Propagasi & Two-ray ground \\
\hline \hline
\end{tabular}

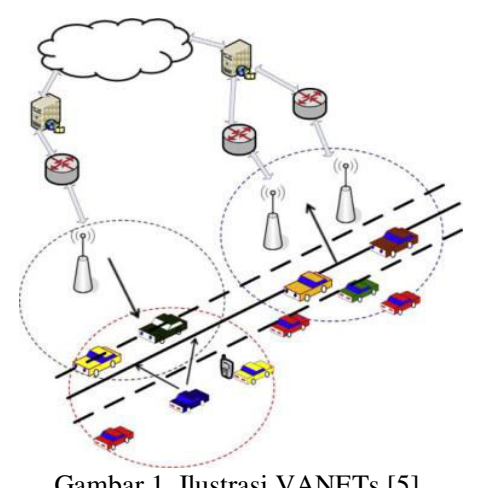

Gambar 1. Ilustrasi VANETs [5].

\section{A. Ad-hoc On Demand Distance Vector (AODV)}

Ad-hoc On Demand Distance Vector (AODV) adalah salah satu routing protokol yang termasuk dalam klasifikasi reactive routing protocol. Sebuah protokol yang hanya membuat sebuah rute saat dibutuhkan. AODV dikembangkan oleh C. E. Perkins, E.M. Belding-Royer dan S. Das pada RFC 3561.

Ada dua tahapan dalam AODV yaitu route discovery dan route maintenance. Route discovery memiliki dua pesan yaitu berupa Route Request (RREQ) dan Route Reply (RREP). Sedangkan Route maintenance berupa Route Error (RERR).

AODV adalah sebuah metode routing pesan antar node yang memungkinkan node-node tersebut untuk melewatkan pesan melalui lingkungannya ke node yang tidak dapat dihubungi secara langsung. AODV melakukan ini dengan cara menemukan rute yang bisa dilalui oleh pesan. Selain itu AODV juga memastikan rute ini tidak mengandung perulangan (loop), menangani perubahan rute, dan membuat rute baru apabila terjadi error [6]. Ilustrasi pencarian rute oleh AODV dapat dilihat pada Gambar 2.

\section{B. Network Simulator-2 (NS-2)}

Network Simulator (NS) adalah suatu interpreter yang berorientasi objek, dan discrete event-driven yang dikembangkan oleh University of California Berkeley dan USC ISI sebagai bagian dari projek Virtual INternet Testbed (VINT). NS yang banyak dikenal dengan NS-2 (versi 2) menjadi salah satu tool yang sangat berguna untuk menunjukkan simulasi jaringan melibatkan Local Area Network (LAN), Wide Area Network (WAN), tapi fungsi dari tool ini telah berkembang selama beberapa tahun belakangan untuk memasukkan jaringan nirkabel (wireless) dan juga jaringan ad hoc [8].

Pada Studi ini, NS-2 digunakan untuk melakukan simulasi lingkungan VANETs menggunakan protokol AODV yang

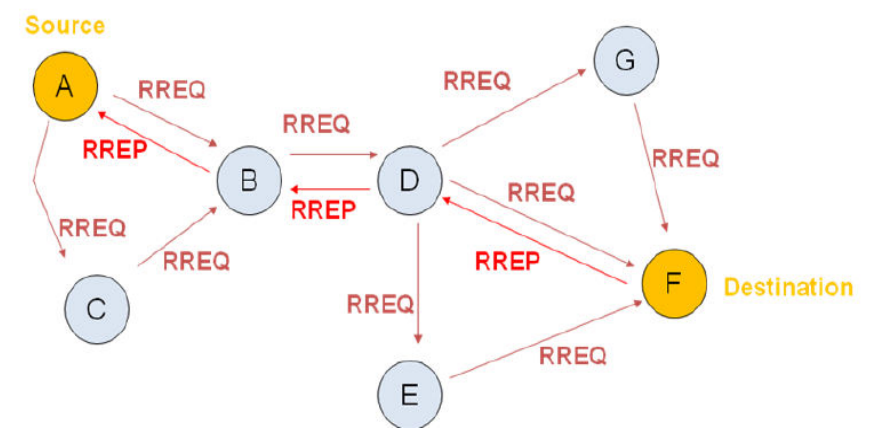

Gambar 2. Ilustrasi Pencarian Rute pada AODV [7].

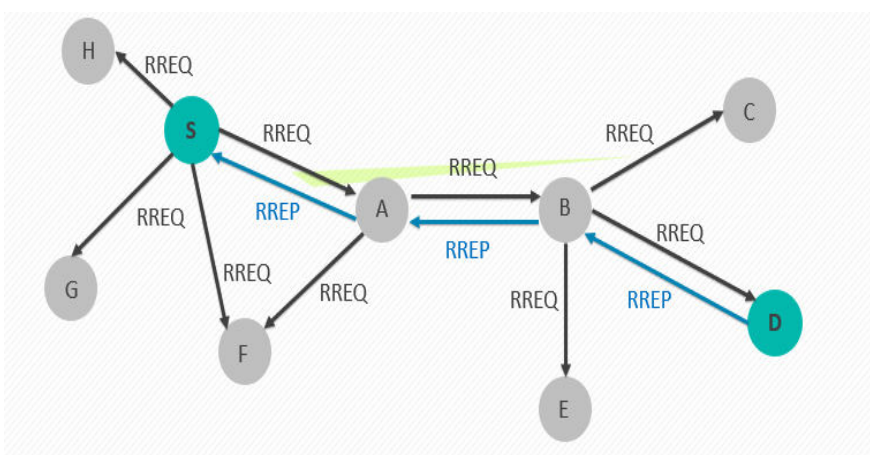

Gambar 3. Ilustrasi Pencarian Rute pada AODV Modifikasi.

sudah dimodifikasi. Trace file yang dihasilkan oleh NS-2 juga digunakan untuk mengukur peforma routing protokol AODV yang sudah dimodifikasi..

\section{Simulation of Urban Mobility (SUMO)}

Simulation of Urban Mobility (SUMO) merupakan paket simulasi lalu lintas yang bersifat open-source dimana pengembangannya dimulai pada tahun 2001. Dan semenjak itu SUMO telah berubah menjadi sebuah simulasi lalu lintas dengan kelengkapan fitur dan pemodelannya termasuk kemampuan jalannya jaringan untuk membaca format yang berbeda.

SUMO juga memungkinkan untuk mendefinisikan kendaraan dengan sifat tertentu seperti panjang kendaraan, kecepatan maksimum, percepatan dan perlambatannya. SUMO juga menyediakan pilihan bagi pengguna menentukan rute acak untuk kendaraan. Ada juga pilihan yang tersedia untuk model sistem transportasi umum, dimana setiap kendaraan datang dan berangkat sesuai dengan jadwal [9].

\section{MODIFIKASI}

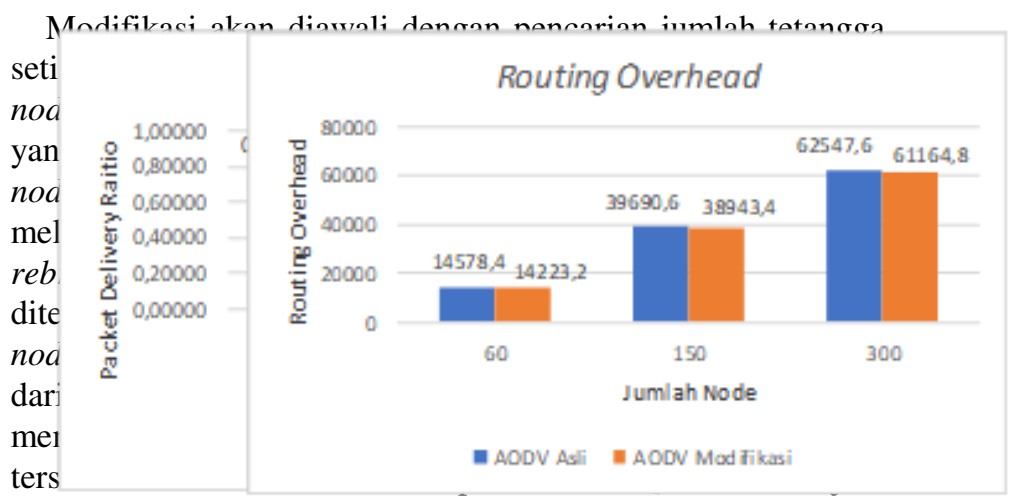

Gambar 4. GrafilGRandkrt D) (inafirk Roticing Overhead. 
sebaliknya, maka node tersebut tidak akan meneruskan paket RREQ atau paket akan di-drop. Ilustrasi pencarian rute oleh AODV yang dimodifikasi dapat dilihat pada Gambar 3. Berikut algoritma modifikasi pada routing protokol AODV.

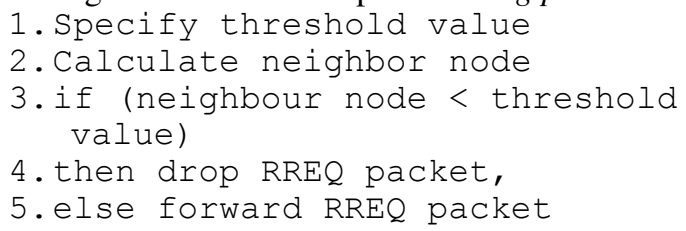

\section{SIMULASI}

Pada bagian ini dijelaskan mengenai lingkungan simulasi dan parameter simulasi untuk melakukan perbandingan performa AODV asli dan AODV modifikasi.

\section{A. Lingkungan Simulasi}

Terdapat 3 jenis lingkungan yang akan digunakan pada simulasi, yaitu 60 node untuk lingkungan jarang, 150 node untuk lingkungan sedang, dan 300 node untuk lingkungan padat.

\section{B. Parameter Simulasi}

Untuk melakukan simulasi, digunakan network simulator NS-2.35 dengan protokol AODV. Skenario yang digunakan berukuran $1500 \mathrm{~m} \times 1500 \mathrm{~m}$. Keterangan lebih lengkap dapat dilihat pada Tabel 1.

\section{HASIL UJI COBA}

Pengujian dilakukan dengan menjalankan skenario yang disimulasikan pada NS-2. Dari simulasi tersebut dihasilkan sebuah trace file dengan ekstensi tr yang akan dianalisis dengan bantuan skrip awk untuk mendapatkan PDR, E2E, RO, dan RREQ. Dilakukan pra uji coba untuk menentukan nilai threshold yang akan dijadikan sebagai perbandingan dengan node tetangga. Penentuan nilai threshold akan dilakukan dengan cara melakukan simulasi dengan threshold yang diambil dari angka satu hingga angka yang membuat nilai Packet Delivery Ratio (PDR), Routing Overhead (RO), dan Forwarded Route Request (RREQ F) pada AODV modifikasi turun secara drastis dibandingkan dengan AODV asli. Pra uji coba dilakukan selama 10 kali dan dilihat hasil metrik analisis yang terbaik dan muncul paling banyak pada 10 skenario tersebut. Hasil yang unggul tersebut akan dijadikan nilai threshold untuk diimplementasikan pada lingkungan uji coba. Dari hasil pra uji coba, didapatkan nilai threshold 9 untuk lingkungan 60 node (jarang), nilai threshold 21 untuk lingkungan 150 node (sedang), dan nilai threshold 45 untuk lingkungan 300 node (padat). Untuk perbandingan hasil pengujian dapat dilihat masing - masing pada Gambar 4, Gambar 5, Gambar 6, dan Gambar 7.

Berdasarkan grafik pada Gambar 4, dapat dilihat bahwa routing protocol AODV asli dan AODV yang telah dimodifikasi mengalami penurunan yang signifikan pada PDR. Pada lingkungan yang jarang dengan node berjumlah 60, menghasilkan perbedaan selisih PDR sebesar 0,04514, dimana terjadi kenaikan PDR sebesar 5,43\% dan routing protocol AODV yang dimodifikasi unggul dalam hal PDR tersebut.
Pada lingkungan yang sedang dengan jumlah 150 node, menghasilkan perbedaan selisih PDR sebesar 0,02484, dimana terjadi kenaikan PDR sebesar 3,02\% dan routing protocol AODV yang dimodifikasi unggul dalam hal PDR tersebut dari AODV asli. Pada lingkungan yang padat dengan jumlah 300 node, menghasilkan perbedaan selisih PDR sebesar 0,12988, dimana terjadi kenaikan sebesar $19,12 \%$ dan routing protocol AODV yang telah dimodifikasi juga unggul dalam hal PDR tersebut. Nilai rata-rata kenaikan PDR pada skenario real adalah sebesar 9,19\%.

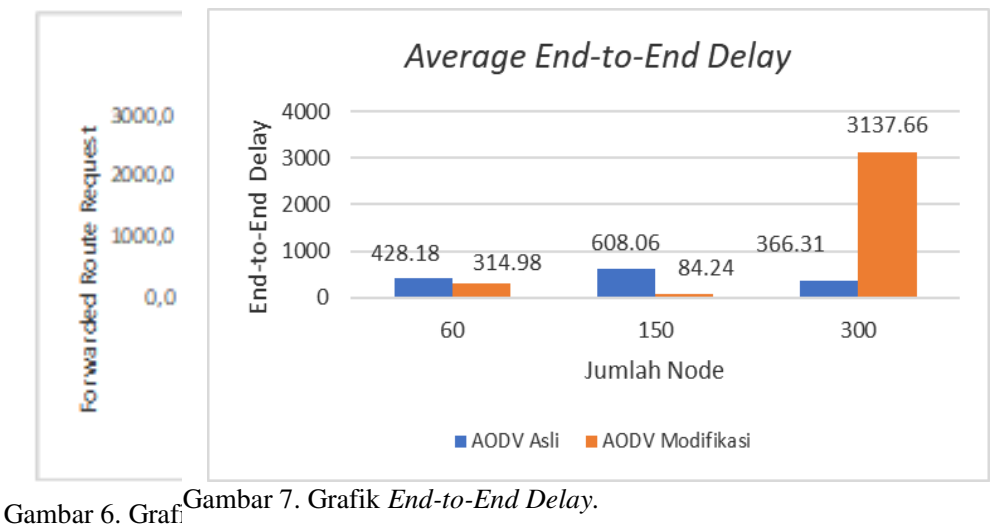

Berdasarkan grafik pada Gambar 5, dapat dilihat bahwa routing protocol AODV yang telah dimodifikasi dan juga routing protocol AODV asli mengalami kenaikan routing overhead. Pada lingkungan yang jarang dengan jumlah 60 node, menghasilkan perbedaan selisih RO sebesar 2144, dimana terjadi penurunan $\mathrm{RO}$ sebesar $2,43 \%$ dan routing protocol AODV yang telah dimodifikasi unggul dalam hal RO tersebut karena menghasilkan $\mathrm{RO}$ yang lebih rendah dari AODV asli. Pada lingkungan yang sedang dengan jumlah 150 node, menghasilkan perbedaan selisih routing overhead sebesar 747.2, dimana terjadi penurunan RO sebesar 1,88\% dan routing protocol AODV yang telah dimodifikasi unggul dalam hal RO tersebut dari AODV asli. Pada lingkungan yang padat dengan jumlah 300 node, menghasilkan perbedaan selisih RO sebesar 1382.8, dimana terjadi penurunan RO sebesar 2,21\% dan routing protocol AODV yang telah dimodifikasi juga unggul dalam hal RO tersebut. Nilai rata rata penurunan PDR pada simulasi real adalah sebesar 2,17\%. Dapat dilihat pula bahwa AODV yang telah dimodifikasi menghasilkan RO yang lebih bagus atau dalam hal ini lebih rendah daripada AODV asli.

Berdasarkan grafik pada Gambar 6, dapat dilihat bahwa routing protocol AODV yang telah dimodifikasi dan juga routing protocol asli mengalami perubahan forwarded route request (RREQ F) yang signifikan. Pada lingkungan yang jarang dengan jumlah 60 node, menghasilkan perbedaan selisih forwarded route request sebesar 304.4, dimana terjadi penurunan RREQ F sebesar 14,20\% dan routing protocol AODV yang telah dimodifikasi unggul dalam hal RREQ $F$ tersebut karena menghasilkan RREQ F yang lebih rendah dari routing protocol AODV asli. Pada lingkungan yang sedang dengan jumlah 150 node, menghasilkan perbedaan selisih forwarded route request sebesar 683, dimana terjadi penurunan RREQ F sebesar $31,23 \%$ dan routing protocol 
AODV yang telah dimodifikasi unggul dalam RREQ $F$ tersebut dari RREQ F AODV asli. Pada lingkungan yang padat dengan jumlah 300 node, menghasilkan perbedaan selisih RREQ F sebesar 1370.6, dimana terjadi penurunan RREQ F sebesar 49,44\% dan routing protocol AODV yang telah dimodifikasi juga unggul dalam hal RREQ F tersebut. Nilai rata-rata penurunan RREQ F pada skenario real adalah sebesar $31,62 \%$. Dapat dilihat pula bahwa AODV yang telah dimodifikasi menghasilkan RREQ F yang lebih bagus atau dalam hal ini lebih rendah daripada RREQ $F$ asli dengan jumlah selisih RREQ F yang cukup signifikan.

Berdasarkan grafik pada Gambar 7, dapat dilihat bahwa rata-rata E2E antara routing protocol AODV asli dan AODV yang telah dimodifikasi mengalami perubahan yang fluktuatif. Pada lingkungan yang jarang dengan jumlah 60 node, terjadi perbedaan selisih end-to-end delay sebesar $113.2008 \mathrm{~ms}$ antara routing protocol AODV asli dengan routing protocol AODV yang telah dimodifikasi, dimana routing protocol AODV yang dimodifikasi unggul dalam hal E2E tersebut. Sedangkan pada lingkungan sedang dengan jumlah 150 node, terjadi perbedaan selisih end-to-end delay sebesar $523.823 \mathrm{~ms}$ antara routing protocol AODV asli dengan routing protocol AODV yang telah dimodifikasi, dimana routing protocol AODV yang tleah dimodifikasi lebih unggul dalam hal E2E. Pada lingkungan yang padat dengan jumlah 300 node, terjadi perbedaan selisih E2E sebesar $2771.35632 \mathrm{~ms}$ antara routing protocol AODV asli dengan routing protocol AODV yang telah dimodifikasi, dimana routing protocol AODV yang asli jauh lebih unggul dalam hal end-to-end delay tersebut.

Jika ketiga lingkungan tersebut dibandingkan, memang pada lingkungan yang jarang, sedang, maupun padat tidak selalu lebih unggul dalam hal E2E. Hasil rata - rata E2E tidak dapat dianalisis karena terjadi fluktuasi dan tidak stabil. Hal ini dikarenakan waktu delay tergantung dari rata - rata waktu paket yang terkirim. Semakin banyak paket yang terkirim, maka semakin beragam delaynya.

\section{KESIMPULAN DAN SARAN}

Setelah dilakukan uji coba, didapatkan kesimpulan sebagai berikut:

Penulis wajib menghindarkan artikelnya dari kemungkinan plagiarisme.

1) AODV yang dimodifikasi sudah berhasil membatasi jumlah forwarding node yang bertugas untuk rebroadcast paket RREQ.

2) Dampak pembatasan forwarding node terhadap performa protokol AODV secara keseluruhan adalah rata - rata kenaikan Packet Delivery Ratio (PDR) sebesar 9,19\%, rata - rata penurunan Routing Overhead (RO) sebesar 2,17\%, dan rata - rata penurunan Forwarded Route Request (RREQ F) sebesar 31,62\%.

Adapun saran-saran yang diberikan untuk pengembangan Studi ini adalah sebagai berikut:

1) Lebih banyak uji coba yang dilakukan untuk mendapatkan hasil yang lebih akurat.

2) Perhitungan jumlah node tetangga yang lebih dinamis pada routing protocol AODV. Contohnya saat node tetangga menjauh dari jangkauan, maka ada mekanisme untuk memperbarui list simpanan node tetangga sehingga perhitungan jumlah node tetangga lebih akurat.

3) Menambahkan aspek lain untuk melakukan pembatasan forwarding node yang meneruskan paket seperti arah, kecepatan, dan energi.

\section{DAFTAR PUSTAKA}

[1] "VANET - Vehicle Ad hoc Network," [Online]. Available: http://comp.ist.utl.pt/ rmr/WSN/CaseStudies2007no/WSN_Transportation/. [Diakses 15 November 2017].

[2] P. Jacquet, P. Muhlethaler, T. Clausen, A. Laouiti, A. Qayyum dan L. Viennot, "Optimized Link State Routing Protocol for Ad hoc Networks," IEEE, Lahore, 2001.

[3] S. N. Ferdous dan M. S. Hossain, "Randomized Energy-Based AODV Protocol for Wireless Ad-Hoc Network," IEEE, Dhaka, 2016.

[4] R. Brendha dan V. S. J. Prakash, "A Survey on Routing Protocols for Vehicular Ad hoc Networks," IEEE, Coimbatore, 2017.

[5] R. G. Engoulou, M. Bellaiche, S. Pierre dan A. Quintero, "VANET Security Surveys," Computer Communication, vol. 44, p. 2, 2014.

[6] R. Brendha dan V. S. J. Prakash, "A Survey on Routing Protocols for Vehicular Ad hoc Networks," IEEE, Coimbatore, 2017.

[7] M. Iqbal, M. Shafiq, H. Attaullah, J.-G. Choi, K. Akram dan X. Wang, "Design and Analysis of a Novel Hybrid Wireless Mesh Network Routing Protocol,” p. 22, January 2014.

[8] P. Meeneghan dan D. Delaney, "An Introduction to NS Nam and OTcl scripting," April 2004.

[9] D. Krajzewics, J. Erdmann, M. Behrisch dan L. Bieker, "Recent Development and Application of SUMO," International Journal On Advances in Systems and Measurements, p. 128, December 2012. 